\title{
The impact of attention deficit hyperactivity disorder on recovery from mild traumatic brain injury
}

\author{
Clinical article
}

\author{
Christopher M. Bonfield, M.D., ${ }^{1}$ SAndi Lam, M.D., M.B.A., ${ }^{2}$ Yimo Lin, B.A., ${ }^{2}$ \\ and Stephanie Greene, M.D. ${ }^{1}$
}

${ }^{1}$ Department of Neurosurgery, Children's Hospital of Pittsburgh, University of Pittsburgh, Pennsylvania; and ${ }^{2}$ Section of Neurosurgery, University of Chicago, Illinois

\begin{abstract}
Object. Attention deficit hyperactivity disorder (ADHD) and traumatic brain injury (TBI) are significant independent public health concerns in the pediatric population. This study explores the impact of a premorbid diagnosis of ADHD on outcome following mild TBI.

Methods. The charts of all patients with a diagnosis of mild closed head injury (CHI) and ADHD who were admitted to Children's Hospital of Pittsburgh between January 2003 and December 2010 were retrospectively reviewed after institutional review board approval was granted. Patient demographics, initial Glasgow Coma Scale (GCS) score, hospital course, and King's Outcome Scale for Childhood Head Injury (KOSCHI) score were recorded. The results were compared with a sample of age-matched controls admitted with a diagnosis of CHI without ADHD.

Results. Forty-eight patients with mild CHI and ADHD, and 45 patients with mild CHI without ADHD were included in the statistical analysis. Mild TBI due to CHI was defined as an initial GCS score of 13-15. The ADHD group had a mean age of 12.2 years (range 6-17 years), and the control group had a mean age of 11.14 years (range 5-16 years). For patients with mild TBI who had ADHD, 25\% were moderately disabled (KOSCHI Score 4b), and $56 \%$ had completely recovered (KOSCHI Score $5 \mathrm{~b}$ ) at follow-up. For patients with mild TBI without ADHD, $2 \%$ were moderately disabled and $84 \%$ had completely recovered at follow-up $(\mathrm{p}<0.01)$. Patients with ADHD were statistically significantly more disabled after mild TBI than were control patients without ADHD, even when controlling for age, sex, initial GCS score, hospital length of stay, length of follow-up, mechanism of injury, and presence of other (extracranial) injury.

Conclusions. Patients who sustain mild TBIs in the setting of a premorbid diagnosis of ADHD are more likely to be moderately disabled by the injury than are patients without ADHD.
\end{abstract} (http://thejns.org/doi/abs/10.3171/2013.5.PEDS12424)

\section{KEY WoRDs • attention deficit hyperactivity disorder • traumatic brain injury • closed head injury $\bullet$ trauma $\bullet$ disability}

$\mathrm{T}$ Raumatic brain injury in children and adolescents is a significant public health concern, with an estimated incidence of 250 per 100,000 per year. Traumatic brain injury results in more than 7000 deaths, 60,000 hospitalizations, and 600,000 emergency room visits annually among American children. ${ }^{13,14}$ In the US, TBI is the leading cause of childhood death and longterm disability, and is one of the most frequent causes of interruption to normal child development. ${ }^{9,14}$

\footnotetext{
Abbreviations used in this paper: $\mathrm{ADHD}=$ attention deficit hyperactivity disorder; ATV = all-terrain vehicle; $\mathrm{CHI}=$ closed head injury; GCS = Glasgow Coma Scale; KOSCHI = King's Outcome Scale for Childhood Head Injury; LOS = hospital length of stay; $\mathrm{MVC}=$ motor vehicle collision; $\mathrm{sADHD}=$ secondary ADHD; SES $=$ socioeconomic status; $\mathrm{TBI}=$ traumatic brain injury.
}

Attention deficit hyperactivity disorder is a neurobehavioral disorder characterized by degrees of inattention and hyperactivity, and often leads to functional impairment academically, socially, and emotionally., ${ }^{1,3}$ In 2003 , approximately $7.8 \%(4,418,000)$ of children in the US between the ages of 4 and 17 years had ever had a diagnosis of ADHD. ${ }^{3}$ Children with ADHD are more vulnerable to psychiatric comorbidities ${ }^{2}$ as well as to long-term economic disadvantages as adults. ${ }^{10}$

There has been a growing body of literature supporting the hypothesis that ADHD and TBI are linkedADHD has been shown to increase the likelihood of TBI events, ${ }^{5,7}$ TBI can lead to a form of ADHD known as secondary ADHD, ${ }^{12,17}$ and preexisting ADHD leads to worse outcomes after a TBI event. The intent of this paper is to explore the last hypothesis: that children with ADHD 


\section{M. Bonfield et al.}

who experience a mild TBI become more disabled than children who do not have ADHD. Specifically, this paper examines children with TBI from CHIs.

\section{Methods}

\section{Study Design}

The charts of all patients with diagnoses of $\mathrm{CHI}$ and ADHD who were admitted to Children's Hospital of Pittsburgh between January 2003 and May 2010 were retrospectively reviewed. Only patients with mild $\mathrm{CHI}$ (defined as an initial GCS score of 13-15) were included in this study. The diagnosis of ADHD was made by a physician prior to this hospitalization, and was either recorded in the patient's medical history or reported by the parents at the time of the CHI admission. The results were compared with a randomly selected sample of agematched controls admitted with a diagnosis of mild CHI without ADHD. The control patients were selected by a computer random-number generator. Forty-eight patients with ADHD and mild CHI and 45 with mild $\mathrm{CHI}$ without ADHD were included in the statistical analysis. These patients were all evaluated as a Level 1 or 2 trauma at Children's Hospital of Pittsburgh. The diagnosis of CHI was made by pathological findings on cranial imaging, mechanism of injury, or a history of loss of consciousness. Patient demographic data, mechanism of injury, hospital course, initial nonpharmacologically influenced GCS score, and KOSCHI score at the latest clinical outpatient follow-up were recorded. This study was approved by the institutional review board at the University of Pittsburgh.

\section{Injury Severity and Outcome Measures}

The GCS is a standardized severity scale used in the acute phase after brain injury, and may predict short- and long-term functional outcome. ${ }^{18}$ Originally, it was used to classify injury severity. ${ }^{16}$ As in previous papers, we used the initial nonpharmacologically influenced GCS score on admission to the emergency room as the measure of injury severity (mild injury is designated by a GCS score of $13-15) .{ }^{11}$

For adults, the Glasgow Outcome Scale is widely used as a measure of long-term disability following TBI. ${ }^{8}$ However, the KOSCHI has been developed to measure outcomes following $\mathrm{CHI}$ in children; it is based on the Glasgow Outcome Scale, but with increased sensitivity at the milder end of the disability range. ${ }^{4}$ In this study, outcomes were calculated using KOSCHI scores derived from chart review of the latest outpatient follow-up. The KOSCHI (Table 1) contains 5 main categories: 1) death, 2) vegetative, 3) severe disability, 4) moderate disability, and 5) good recovery. Categories 3, 4, and 5 are subdivided into a) more deficits and b) fewer deficits. To adjust for baseline differences in disability between children with ADHD and those without, only new disabilities were included in KOSCHI scores during the review of patient outcomes. New disabilities were determined by questioning the patients and their families during follow-up outpatient appointments regarding pre- and posttrauma functioning. This was done by the clinical neurosurgi- cal team (attending neurosurgeons, neurosurgical residents, and neurosurgical physician assistants), who had no knowledge of a future study.

\section{Statistical Analyses}

Comparisons of demographic and patient factors between the ADHD and control groups were determined using 2-tailed Fisher exact t-tests. Outcomes were calculated using the KOSCHI scale, and results were also compared between the two groups according to injury severity by using 2-tailed Fisher exact t-tests. In addition, a multivariate regression analysis was performed to determine the association between mild TBI and KOSCHI score adjusted for various demographic and patient factors. For this analysis the KOSCHI score was coded on a continuous scale of 1 to 2 to 3 , representing $4 \mathrm{~b}$ to $5 \mathrm{a}$ to $5 \mathrm{~b}$ (no samples in the cohort had a score lower than 4b); 1 unit of disability was counted as a change from $4 \mathrm{~b}$ to $5 \mathrm{a}$ or from $5 \mathrm{a}$ to $5 \mathrm{~b}$. The statistical analyses were performed using STATA version 12 . Statistical significance was set at $\mathrm{p}<0.05$.

\section{Results}

Forty-eight patients with ADHD and mild CHI and 45 randomly selected age-matched patients with mild CHI without ADHD were included in the statistical analysis. Demographic data and initial GCS score are shown in Table 2. In both groups, the majority of patients were males $(90 \%$ ADHD vs $78 \%$ control, $\mathrm{p}=0.12)$. Neither patient age (12.2 years ADHD vs 11.1 years control, $\mathrm{p}=$ $0.27)$ nor initial GCS score on presentation to the hospital (14.7 ADHD vs 14.5 control, $p=0.09$ ) were significantly different between the groups.

The most common mechanisms of injury (Table 3 ) in the ADHD group were falls $(17 \%)$, pedestrian versus car $(15 \%)$, blunt object to head $(15 \%)$, bicycle accidents $(13 \%)$, and sports accidents $(12.5 \%)$. In the control group, the most common mechanisms of injury were falls $(20 \%)$, MVC (16\%), ATV accident (16\%), and blunt object to head (13\%).

Data regarding the patient's hospital stay was also recorded (Table 4). No one in the study group needed intracranial pressure monitoring, as expected for mild TBIs. A slightly lower rate of surgical treatment of the injury $(10 \%$ ADHD vs $13 \%$ control, $\mathrm{p}=0.67)$, and a slightly longer LOS (3.63 days ADHD vs 2.33 days control, $\mathrm{p}=0.22$ ) were found in the ADHD group. None of these comparisons reached statistical significance. The patients' disposition from the hospital were similar between the two groups as well $(\mathrm{p}=0.33)$ : in the ADHD group 98\% were discharged home and $2 \%$ transferred to a rehabilitation center, with $100 \%$ discharged home in the control group. The mean follow-up time after mild TBI was 24.9 weeks (range 2-208 weeks) for the ADHD group and 7.2 weeks (range 3-60 weeks) for the control group $(\mathrm{p}=0.01)$.

Outcome data are displayed in Table 5. For mild CHI patients with ADHD, 25\% were moderately disabled at follow-up (KOSCHI 4b) compared with $2 \%$ of mild CHI patients without ADHD. For mild CHI patients with ADHD, only $56 \%$ had a complete recovery with no detectable sequelae from the injury (KOSCHI 5b), compared with $84 \%$ in the control group $(\mathrm{p}<0.01)$. 


\section{Attention deficit hyperactivity disorder recovery after mild TBI}

\section{TABLE 1: King's Outcome Scale for Childhood Head Injury (KOSCHI) ${ }^{6 *}$}

\begin{tabular}{|c|c|c|}
\hline \multicolumn{2}{|c|}{ Category } & \multirow[t]{2}{*}{ Definition } \\
\hline 1 & Death & \\
\hline 2 & Vegetative & $\begin{array}{l}\text { The child is breathing spontaneously and may have sleep/wake cycles. He may have non-purposeful or reflex move- } \\
\text { ments of limbs or eyes. There is no evidence of ability to communicate verbally or non-verbally or to respond to com- } \\
\text { mands. }\end{array}$ \\
\hline 3 & Severe disability & $\begin{array}{l}\text { (a) The child is at least intermittently able to move part of the body/eyes to command or make purposeful spontaneous } \\
\text { movements; for example, confused child pulling at nasogastric tube, lashing out at carers, rolling over in bed. May be } \\
\text { fully conscious and able to communicate but not yet able to carry out any self care activities such as feeding. } \\
\text { (b) Implies a continuing high level of dependency, but the child can assist in daily activities; for example, can feed self or } \\
\text { walk with assistance or help to place items of clothing. Such a child is fully conscious but may still have a degree of } \\
\text { post-traumatic amnesia. }\end{array}$ \\
\hline 4 & Moderate disability & $\begin{array}{l}\text { (a) The child is mostly independent but needs a degree of supervision/actual help for physical or behavioral problems. } \\
\text { Such a child has overt problems; for example, } 12 \text { year old with moderate hemiplegia and dyspraxia insecure on stairs } \\
\text { or needing help with dressing. } \\
\text { (b) The child is age appropriately independent but has residual problems with learning/behavior or neurological se- } \\
\text { quelae affecting function. He probably should have special needs assistance but his special needs may not have } \\
\text { been recognized/met. Children with symptoms of post-traumatic stress are likely to fall into this category. }\end{array}$ \\
\hline 5 & Good recovery & $\begin{array}{l}\text { (a) This should only be assigned if the head injury has resulted in a new condition which does not interfere with the } \\
\text { child's well being and/or functioning; for example: } \\
\text { - Minor headaches not interfering with social or school functioning } \\
\text { - Abnormalities on brain scan without any detectable new problem } \\
\text { - Prophylactic anticonvulsants in the absence of clinical seizures } \\
\text { - Unsightly scarring of face/head likely to need cosmetic surgery at some stage } \\
\text { - Mild neurological asymmetry but no evidence of affect on function of limb. Includes isolated change in hand domi- } \\
\text { nance in young child. } \\
\text { (b) Implies that the information available is that the child has made a complete recovery with no detectable sequelae } \\
\text { from the head injury. }\end{array}$ \\
\hline
\end{tabular}

* Reproduced with permission from the BMJ Publishing Group Ltd. Reprinted from Crouchman M, Rossiter L, Colaco T, et al: A practical outcome scale for paediatric head injury. Arch Dis Child 84:120-124, 2001.

The associations between mild TBI and KOSCHI score adjusted for patient and demographic factors are shown in Table 6 . These associations are not statistically significantly impacted by sex, initial GCS score, LOS, other (that is, noncranial) injuries, or most mechanisms of injury. They are statistically significantly impacted by age $(\beta=-0.047, \mathrm{CI}-0.089$ to -0.006$)$; length of follow-

TABLE 2: Characteristics in 48 patients with ADHD and CHI and in 45 patients with $\mathrm{CHI}$ only

\begin{tabular}{lcc}
\hline \multicolumn{1}{c}{ Characteristic } & ADHD (\%) & Control (\%) \\
\hline sex $(p=0.12)$ & & \\
male & $43(90)$ & $35(78)$ \\
female & $5(10)$ & $10(22)$ \\
total & $48(100)$ & $45(100)$ \\
age in yrs $(p=0.27)$ & & \\
mean & 12.15 & 11.14 \\
range & $6-17$ & $5-16$ \\
SD & 2.74 & 3.24 \\
initial GCS score $(p=0.09)$ & & \\
mean & 14.72 & 14.51 \\
range & $13-15$ & $13-15$ \\
SD & 0.57 & 0.66 \\
\hline
\end{tabular}

up ( $\beta=-0.01, \mathrm{CI}-0.014$ to -0.006$)$; and a diagnosis of $\operatorname{ADHD}(\beta=-0.305, \mathrm{CI}-0.555$ to -0.056$)$. These associations are also statistically significantly impacted by having a mechanism of injury of MVC $(\beta=0.45, \mathrm{CI}-0.026$ to 0.882 ) or a sports accident ( $\beta=0.651, \mathrm{CI} 0.21$ to 1.09 ). The model had an $\mathrm{R}^{2}$ of 0.5 and an adjusted $\mathrm{R}^{2}$ of 0.41 .

\section{Discussion}

This study was conducted to assess the impact of a premorbid diagnosis of ADHD on outcome after CHI among children. Demographic data, hospital stay, follow-

\section{TABLE 3: Mechanism of injury in 48 patients with ADHD and CHI} and in 45 patients with $\mathrm{CHI}$ only

\begin{tabular}{lll}
\hline \multicolumn{1}{c}{ Mechanism } & ADHD (\%) & Control (\%) \\
\hline fall & $8(17)$ & $9(20)$ \\
pedestrian vs car & $7(15)$ & $5(11)$ \\
blunt object to head & $7(15)$ & $6(13)$ \\
bicycle accident & $6(12.5)$ & $4(9)$ \\
sports accident & $6(12.5)$ & $5(11)$ \\
MVC & $5(10)$ & $7(16)$ \\
ATV accident & $3(6)$ & $7(16)$ \\
other & $6(12.5)$ & $2(4)$ \\
\hline
\end{tabular}


TABLE 4: Inpatient course in 48 patients with ADHD and CHI and in 45 patients with $\mathrm{CHI}$ only

\begin{tabular}{lcc}
\hline \multicolumn{1}{c}{ Inpatient Course } & ADHD (\%) & Control (\%) \\
\hline $\begin{array}{l}\text { surgery }(p=0.67) \\
\text { yes }\end{array}$ & $5(10)$ & $6(13)$ \\
no & $43(90)$ & $39(87)$ \\
LOS in days $(p=0.22)$ & & \\
$\quad$ mean & 3.63 & 2.33 \\
range & $0-48$ & $1-8$ \\
SD & 6.88 & 1.37 \\
disposition $(p=0.33)$ & & \\
home & $47(98)$ & $45(100)$ \\
rehabilitation & $1(2)$ & 0 \\
follow-up time in wks $(p=0.01)$ & & \\
mean & 24.9 & 7.2 \\
range & $2-208$ & $3-60$ \\
SD & 46.3 & 8.7 \\
\hline
\end{tabular}

up, and outcome information were recorded and compared between children with and without ADHD who experienced mild CHIs. We found that after a mild CHI, children who have ADHD experience more disability at follow-up when compared with controls who do not have ADHD, even when adjusting for sex, age, initial GCS score, LOS, mechanism of injury, and presence of other (non-TBI) types of injuries. We also found that older age and certain mechanisms of injury (MVC, sports injuries) were predictive of a worse outcome in both ADHD and control groups.

Our data show that after a mild CHI, children who have ADHD are more disabled than controls who do not have ADHD as measured by the KOSCHI. After a mild injury, $98 \%$ of the control patients were back to

TABLE 5: KOSCHI scores in 48 patients with ADHD and CHI and in 45 patients with $\mathrm{CHI}$ only*

\begin{tabular}{ccc}
\hline KOSCHI Category & ADHD (\%) & Control (\%) \\
\hline 1 death & 0 & 0 \\
2 vegetative & 0 & 0 \\
2a & 0 & 0 \\
$2 b$ & 0 & 0 \\
3 severe disability & 0 & 0 \\
3a & 0 & 0 \\
$3 b$ & 0 & 0 \\
4 moderate disability & $12(25)$ & $1(2)$ \\
$4 a$ & 0 & 0 \\
$4 b$ & $12(25)$ & $1(2)$ \\
5 good recovery & $36(75)$ & $44(98)$ \\
$5 a$ & $9(19)$ & $6(13)$ \\
$5 b$ & $27(56)$ & $38(84)$ \\
total & $48(100)$ & $45(100)$ \\
\hline
\end{tabular}

* ADHD vs control: $p<0.01$. Subcategory $a=$ more deficits; $b=$ fewer deficits. baseline functioning and $84 \%$ had recovered completely with no sequelae by the last follow-up (mean 7.2 weeks), whereas $25 \%$ of the ADHD patients were still moderately disabled, and only $56 \%$ had recovered completely, even after a statistically significantly longer follow-up (mean 25 weeks). Compared with children without ADHD, children with ADHD have a lower KOSCHI score at followup by a factor of 0.3 , even when controlling for age, sex, initial GCS score, LOS, length of follow-up, mechanism of injury, and the presence of other (non-TBI) injuries. There are numerous explanations for these data: perhaps children with ADHD are more vulnerable to brain injury, perhaps ADHD impairs the healing process, or perhaps rehabilitation programs are less effective for children with ADHD.

Alternate explanations for these findings include the following. At baseline, children with ADHD may be more disabled than their peers, and so comparisons on the KOSCHI will find more disability in the ADHD versus control group after TBI. We attempted to adjust for this by only including injuries that were not present before the TBI in the KOSCHI score. It is possible that the TBI may unmask characteristics of premorbid ADHD, which would lead to the appearance of new symptoms. We acknowledge that, fundamentally, we cannot distinguish whether a "new" disability after TBI was due to the TBI or to an unmasked symptom of previously diagnosed ADHD.

Another explanation relates to the theory that SES predicts worse outcomes after TBI. ${ }^{17}$ There is an association between lower SES and the incidence of ADHD. ${ }^{15}$ It is possible that in this study ADHD is acting as a proxy for low SES, and that low SES, not ADHD, is leading to worse outcomes after TBI. We cannot disprove this because SES data were not collected, but the magnitude of the outcome disparity after TBI between the ADHD and non-ADHD group in this study is larger than the outcome disparity after TBI between the low- and high-SES groups reported in the literature..$^{17}$

A final possible alternate explanation is that TBI can cause an ADHD-like syndrome called SADHD. ${ }^{12,17}$ There are data suggesting that children with ADHD are more likely to develop SADHD after TBI, ${ }^{12}$ in which case the increased disability we see in the ADHD group may be a manifestation of sADHD. However, other studies have shown that children with preinjury ADHD who did not develop sADHD still have worse outcomes after TBI when compared with their peers who do not have ADHD. ${ }^{12}$

The data also show a very subtle $(\beta=-0.05, \mathrm{CI}-0.09$ to -0.01 ) but statistically significant inverse relationship between age and disability after TBI. Such a subtle result in a small, single-center study is difficult to interpret. The data also show a statistically significant relationship between certain mechanisms of injury and worse outcomes after TBI: MVC and sports accidents seemed to lead to more disability as measured by the KOSCHI when controlling for age, sex, GCS score, LOS, follow-up time, ADHD diagnosis, and associated (noncranial) injuries. Although interesting, the sample sizes for each mechanism of injury are small, and further investigations are 


\section{Attention deficit hyperactivity disorder recovery after mild TBI}

TABLE 6: Multivariate analysis of predictors of KOSCHI score after mild TBI in pediatric patients*

\begin{tabular}{lccc}
\hline \multicolumn{1}{c}{ Variable } & $\beta$ & $\mathrm{Cl}$ & $\mathrm{p}$ Value \\
\hline age & -0.047 & -0.089 to -0.006 & 0.026 \\
male sex & -0.067 & -0.411 to 0.277 & 0.698 \\
GCS score & 0.192 & -0.012 to 0.395 & 0.064 \\
LOS & 0.007 & -0.019 to 0.033 & 0.577 \\
length of follow-up (wks) & -0.010 & -0.014 to -0.006 & $<0.001$ \\
ADHD diagnosis & -0.305 & -0.555 to -0.056 & 0.017 \\
mechanism of injury & & & reference \\
fall & 0 & reference & 0.038 \\
MVC & 0.454 & -0.026 to 0.882 & 0.118 \\
ATV accident & 0.367 & -0.096 to 0.83 & 0.129 \\
pedestrian vs car & 0.33 & -0.10 to 0.76 & 0.579 \\
bicycle accident & 0.134 & -0.345 to 0.613 & 0.835 \\
blunt object to head & -0.044 & -0.469 to 0.380 & 0.004 \\
sports accident & 0.651 & 0.210 to 1.09 & 0.479 \\
other & -0.175 & -0.664 to 0.314 & reference \\
associated injuries & & & 0.322 \\
no & 0.000 & reference &
\end{tabular}

* Model $R^{2}=0.50$, adjusted $R^{2}=0.41$. Significance level for $p$ values is $<0.05$.

needed before firm conclusions can be drawn. Finally, the multivariate analysis showed an association between length of follow-up time and KOSCHI score: this is expected, because children who are more disabled (as opposed to those who made full recoveries) are expected to be followed for longer periods of time.

The significance of these findings is multifold. This study highlights the importance of preventing TBI in children with ADHD, perhaps by encouraging them to avoid contact sports or hobbies that carry an increased risk of TBI. This is especially pertinent given data that children with ADHD are reported to sustain higher levels of injury, especially $\mathrm{CHI}$, when compared with age-matched controls. ${ }^{5}$ This study may better inform the clinical management in children who have ADHD and experience a CHI, perhaps directing more intensive resources and closer monitoring to encourage maximal recovery. Third, it may spur the education of families of children with ADHD about expectations during the recovery period after TBI. Finally, this study represents another reason to be aggressive about effective ADHD treatment; data exist showing that children with effectively treated ADHD have life outcomes comparable to children without ADHD. ${ }^{6}$

Limitations of this study include the relatively small sample size; it is not sufficiently powered to answer questions about hospital experiences or moderate and severe $\mathrm{CHI}$. Another limitation is that there is only one measure of outcome, the KOSCHI, and so limitations of the scale itself or in the application of the scale directly impact the data of this study. It is possible that the posttraumatic deficits identified in the ADHD group were simply due to the progression of the disease. However, an acute change in behavior due only to disease progression, which corresponds exactly with the timing of the trauma, is highly unlikely. Furthermore, the follow-up time would not have been long enough for the chronic disease to progress to such a degree. Another limitation is that there is only one follow-up point per patient after the TBI event. Further studies with more data points and longer follow-up to capture long-term outcomes are needed.

\section{Conclusions}

Closed head injuries and ADHD among the pediatric population are common and significant public health concerns. In this paper, we report that patients with ADHD who sustained mild CHIs were more likely to be moderately disabled than those sustaining mild CHIs in the absence of premorbid ADHD. This finding may be important in managing treatment in children with ADHD who experience a CHI, in informing families about expectations as a child recovers from the injury, and in emphasizing the importance of TBI prevention in children with ADHD. Further studies are needed to evaluate the impact of ADHD and other conditions on outcome after TBI of increasing severity, and to explore the mechanisms underlying the relationship between these two conditions.

\section{Disclosure}

The authors report no conflict of interest concerning the materials or methods used in this study or the findings specified in this paper.

Author contributions to the study and manuscript preparation include the following. Conception and design: Bonfield, Greene. Acquisition of data: Bonfield. Analysis and interpretation of data: all authors. Drafting the article: all authors. Critically revising the article: all authors. Reviewed submitted version of manuscript: all authors. Approved the final version of the manuscript on behalf of 
all authors: Bonfield. Statistical analysis: all authors. Administrative/ technical/material support: Greene. Study supervision: Greene.

\section{References}

1. Barkley RA: Attention-Deficit Hyperactivity Disorder: A Handbook for Diagnosis and Treatment, ed 2. New York: Guilford Press, 1998

2. Biederman J, Newcorn J, Sprich S: Comorbidity of attention deficit hyperactivity disorder with conduct, depressive, anxiety, and other disorders. Am J Psychiatry 148:564-577, 1991

3. Centers for Disease Control and Prevention: Mental health in the United States. Prevalence of diagnosis and medication treatment for attention-deficit/hyperactivity disorder-United States, 2003. MMWR Morb Mortal Wkly Rep 54:842-847, 2005

4. Crouchman M, Rossiter L, Colaco T, Forsyth R: A practical outcome scale for paediatric head injury. Arch Dis Child 84: 120-124, 2001

5. DiScala C, Lescohier I, Barthel M, Li G: Injuries to children with attention deficit hyperactivity disorder. Pediatrics 102:1415-1421, 1998

6. Faigel HC, Sznajderman S, Tishby O, Turel M, Pinus U: Attention deficit disorder during adolescence: a review. J Adolesc Health 16:174-184, 1995

7. Hoare P, Beattie T: Children with attention deficit hyperactivity disorder and attendance at hospital. Eur J Emerg Med 10:98-100, 2003

8. Jennett B, Bond M: Assessment of outcome after severe brain damage. Lancet 305:480-484, 1975

9. Kraus JF: Epidemiological features of brain injury in children: occurrence, children at risk, causes and manner of injury, severity and outcomes, in Broman SH, Michel ME (eds): Traumatic Head Injury in Children. New York: Oxford University Press, 1995, pp 22-39

10. Küpper T, Haavik J, Drexler H, Ramos-Quiroga JA, Wermelskirchen D, Prutz C, et al: The negative impact of attentiondeficit/hyperactivity disorder on occupational health in adults and adolescents. Int Arch Occup Environ Health 85:837847, 2012

11. Massagli TL, Michaud LJ, Rivara FP: Association between injury indices and outcome after severe traumatic brain injury in children. Arch Phys Med Rehabil 77:125-132, 1996
12. Max JE, Lansing AE, Koele SL, Castillo CS, Bokura H, Schachar R, et al: Attention deficit hyperactivity disorder in children and adolescents following traumatic brain injury. Dev Neuropsychol 25:159-177, 2004

13. National Center for Injury Prevention and Control: Traumatic Brain Injury in the United States: Assessing Outcomes in Children. Atlanta: Centers for Disease Control and Prevention, 2006 (http://www.cdc.gov/traumaticbraininjury/ assessing_outcomes_in_children.html) [Accessed May 15, 2013]

14. Schneier AJ, Shields BJ, Hostetler SG, Xiang H, Smith GA: Incidence of pediatric traumatic brain injury and associated hospital resource utilization in the United States. Pediatrics 118:483-492, 2006

15. Spencer TJ, Biederman J, Wilens TE, Faraone SV: Overview and neurobiology of attention-deficit/hyperactivity disorder. $\mathbf{J}$ Clin Psychiatry 63 (Suppl 12):3-9, 2002

16. Teasdale G, Jennett B: Assessment of coma and impaired consciousness. A practical scale. Lancet 304:81-84, 1974

17. Wassenberg R, Max JE, Lindgren SD, Schatz A: Sustained attention in children and adolescents after traumatic brain injury: relation to severity of injury, adaptive functioning, ADHD and social background. Brain Inj 18:751-764, 2004

18. Zafonte RD, Hammond FM, Mann NR, Wood DL, Black KL, Millis SR: Relationship between Glasgow coma scale and functional outcome. Am J Phys Med Rehabil 75:364-369, 1996

Manuscript submitted September 10, 2012.

Accepted May 13, 2013.

Portions of this work were given as an oral presentation at the AANS/CNS Section on Pediatric Neurosurgery held in Cleveland, Ohio, in December 2010.

Please include this information when citing this paper: published online June 25, 2013; DOI: 10.3171/2013.5.PEDS12424.

Address correspondence to: Christopher M. Bonfield, M.D., Department of Neurosurgery, University of Pittsburgh, 4th Floor Faculty Pavilion, 4401 Penn Ave., Pittsburgh, PA 15224. email: bonfieldcm@upmc.edu. 